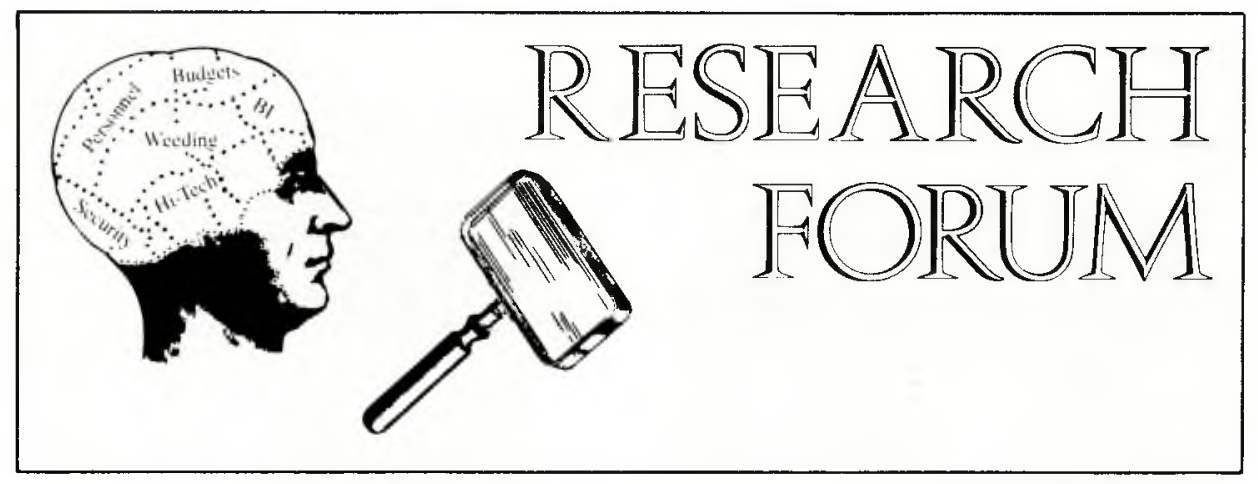

\title{
The research problem
}

\author{
By Ron R. Powell \\ Assistant Professor \\ University of Michigan School of Library Science
}

The logical starting point for any rigorous research, whether it be applied or theoretical, is the problem. In fact, Paul Leedy, a research methodologist, has stated that "the situation is quite simple: no problem, no research." Albert Einstein has been quoted as saying that "the formulation of a problem is often more essential than its solution." This could be a bit of an overstatement, but there is no question that the nature of the research problem is critical to the success of the research effort.

But many doctoral students and practicing librarians, suddenly faced with the prospect of conducting research, discover that research problems are not as easy to identify as one might expect. Why is this the case? Part of the answer lies with the fact that while research problems are all around us, given limitations of time, money and expertise, not all of these problems are researchable. Indeed, the selection of a suitable research problem is often a problem in itself.

In determining whether a problem is likely to be researchable there are several questions that the would-be researcher should ask. Among these questions are:

1. With what academic disciplines is the problem concerned? The answer to this question should indicate in what areas the researcher will need some expertise and/or will need to conduct a literature review.

2. Are the data which will be needed to resolve

\footnotetext{
${ }^{1}$ Paul D. Leedy, Practical Research (New York: Macmillan, 1980), p. 50.

${ }^{2}$ Claire Selltiz, et al., Research Methods in Social Relations (New York: Holt, Rinehart \& Winston, 1959), p. 26.
}

the problem available? For example, if the researcher will need budgetary data for specific libraries, will he or she be able to obtain such information? How much effort will be necessary to obtain the data? How much time and money will it require?

3. Does the researcher have the expertise needed to collect the data? For example, the researcher may need to conduct interviews in order to obtain user evaluations of a library service, but is he or she adequately trained to conduct a proper interview? If not, is expert assistance available and how much will it cost?

4. Are special equipment or facilities necessary in order to gather the research data? If yes, are they available and how much will they cost?

5. Will administrative support, guidance, and cooperation for the research study be provided? This question is particularly important for the practicing librarian who must weigh the importance of doing research against his or her more pressing day-to-day responsibilities.

6. Is the problem clear, precise, specific, and explicit? An oft-quoted statement is that "A question well-stated is a question half-answered." This quotation applies equally well to problems.

7. Is the problem appropriate for research? Some problems are simply too philosophical in nature to be amenable to scientific research.

8. Is the problem of interest to the researcher and relevant to his or her professional goals? A researcher who is not adequately motivated is less

${ }^{3}$ Stephen Isaac and William B. Michael, Handbook in Research and Evaluation (San Diego: Edits Publishers, 1971), p. 2. 
likely to conduct good research and may well fail to complete the study. One is more likely to be interested in research that meshes with his or her educational and work experiences, is relatively new, and is not trivial in nature. One should, of course, determine whether some researcher has already staked out a claim to the research. A variety of approaches to the same problem are generally possible, however.

9. Does the problem represent conceptual thinking and inquiry? A problem that does not meet this criterion probably calls for simple data gathering rather than true research. The collection of statis- tics may be important to the operation of a library and can provide part of the basis for future research, but research that is more than mere activity generally involves the investigation of meaningful concepts and their relationships.

In addition to questions regarding the feasibility of a research problem, the researcher may want to ask questions about the social and professional significance of the problem. But such considerations are probably academic, if all or most of the questions of researchability were not answered adequately.

\title{
Research on community college Learning Resource Services
}

\author{
By W. Lee Hisle \\ Director, Learning Resource Services \\ Austin Community College
}

My paper at ACRL's Third National Conference in Seattle, "Libraries in Learning Resource Services: Has the Cornerstone Become Just Another Block in the Foundation?", was intended to question the impact of growth of Learning Resource Services (LRS) programs on library services in community colleges. I suspected, from my own experience, that increasing the size of the LRS could decrease the influence of a library program. Then in the spring of 1983 the Southern Association of Colleges and Schools sent a visitation team to Austin Community College as part of our reaffirmation of accreditation process.

We had completed a self-study the previous fall identifying the most serious problems and the most laudable aspects of our institution. One particular area for our attention was the organizational structure of the Learning Resource Services, a program that encompassed not only library and media services, but also telecommunications, duplication centers, testing centers, and aspects of instructional television.

Several of us in LRS argued that an organizational structure with intermingled program budgets was problematical; it gave a distorted view of the true size of the library and media services components of the college. The visitation team, including Dr. Gloria Terwilliger, Northern Virginia Community College, agreed and recommended that the college break out the Testing and Duplication Services from the LRS budget.

Terwilliger was instrumental in defining the possible problems for libraries when part of an expansive Learning Resource Services program means less time and effort can be spent providing leadership to library/media services. By combining the budgets together the size of the LRS is distorted. The budget can more easily be interpreted as adequate or even too large. Terwilliger was experiencing a proliferation of services in the LRS at Northern Virginia. She commented that a trend seemed to be developing toward expanded Learning Resource Services in larger community colleges. I took the cue.

After a couple telephone calls and a few convention cocktail hours, I found that other LRS directors were having the same experiences. Without further evidence I could have made a case for limiting the growth of Learning Resource Services and reemphasizing the value of library programs. But I knew my case would be stronger if these few reports of growing LRS programs were representative of a larger universe. I selected (most unrandomly) 40 large community college programs to survey. Essentially I tried to pick colleges that were near my own in terms of size and character. Also I paid attention to geographical distribution and picked colleges from all areas of the United States.

In developing a questionnaire to elicit information from directors of LRS, I kept it simple: only six questions on two pages. Four of the questions were check-off types and two required only minimal writing. If the data requested was near at hand, I estimated no more than 10 minutes would be required to complete the survey. Since the first mailing was done in mid-August and the paper was due to ACRL on October 1, 1983, I did not have time for a follow-up mailing. I hoped the simplicity of the survey and the speed with which it could be completed would encourage a high first-time re- 


\section{DO YOU THINK THIS TO BE A FAIR QUESTION?}
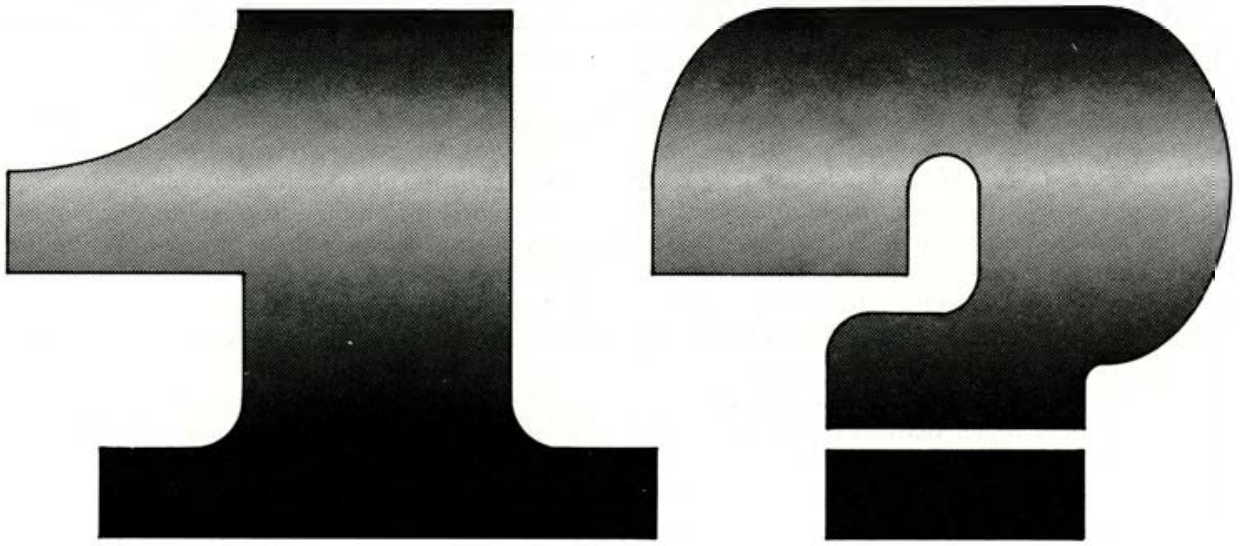

Ask 495 European publishers to standardize their serial bills to

\section{- one format}

\section{- one currency}

- one expiration date

Guess at their answers...

But once you concentrate your subscriptions with SWETS the miracle happens... one currency (US\$ or Can\$), one renewal date, invoice date(s) of your choice.
And with all these publishers... SWETS the key to reliable subscription handling and unrivaled ordering, claiming and paying procedures.

Why go direct or use many agents if SWETS offers a complete solution.

SWETS - a solid bridge between your library and European publishers.

Ask for more information. See coupon below. Thank you.

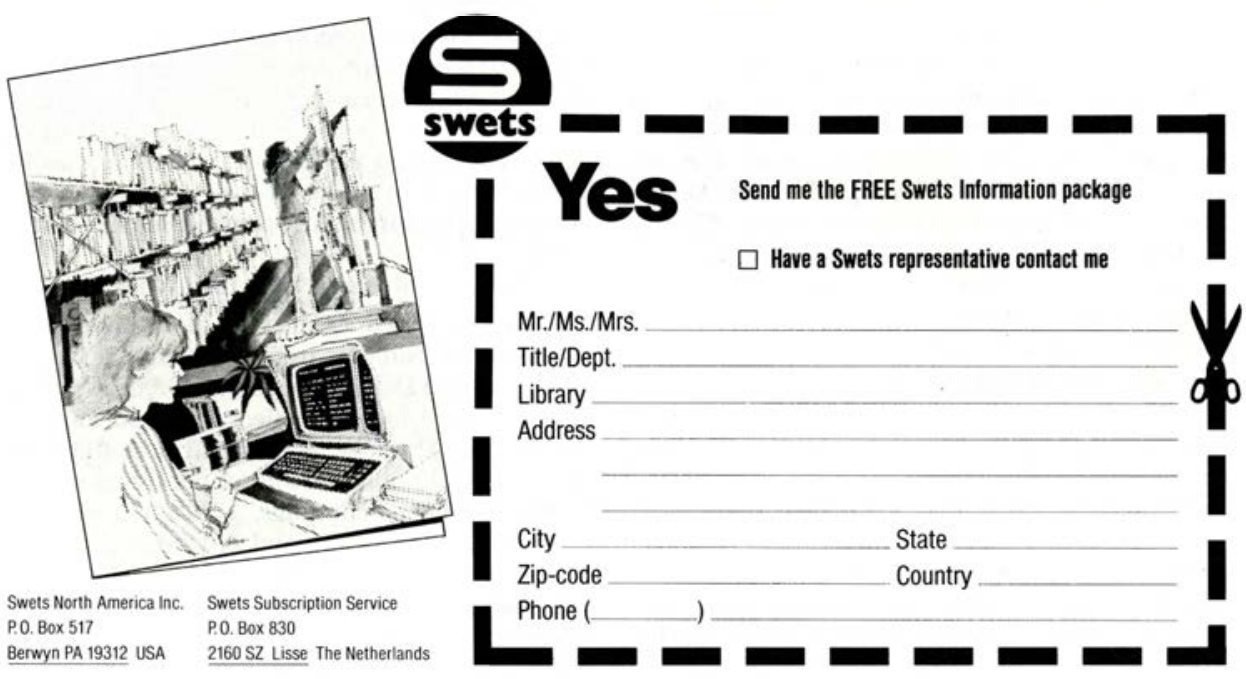


sponse. In fact the response rate was a barely acceptable $57 \%$. Nevertheless, the resluts seemed to substantiate my thesis.

Like the pleading sinner, I yearned: if only I could live my life over. Well, maybe not my whole life, but at least regarding this survey effort I would do a few things differently. The reviewers for the paper all had problems with its research methodology. I was not surprised-it was a real seat-of-thepants effort. Were I to do this survey again, random sampling all community colleges with enrollments over 4,000 FTE would head the list of changes. I have little basis for claiming that my sample was representative. To increase my response rate to a more defensible $80 \%$, I would do a second mailing or a telephone follow-up. Furthermore, the questionnaire should have been pilot tested or at least reviewed by an experienced practitioner in research design. Finally, data elements could have been better defined to ensure that the survey actually measured what it purported to measure.

One final note: the ACRL conference was excel- lent; but with only one contributed paper, one group session, and one theme speaker, community colleges were under-represented. It's our own fault. One of the problems in community college librarianship and in community colleges in general, is the lack of required or even encouraged research. Unlike their college and university counterparts, in order to be retained and promoted, community college librarians and faculty rarely perform original, publishable research and may even be discouraged from doing so as irrelevant to the teaching and service mission of a community college.

Of course it's a ludicrous position. Without evaluation our programs cannot improve. Without the concentrated study and analysis research requires, we may become superficial. Unfortunately the lack of research is part of our community college environment. We slug through the mud and rarely look to the sky. I suggest that we must look to the skyresearch will be an essential means of establishing our college and program validity in the coming hard times in higher education.

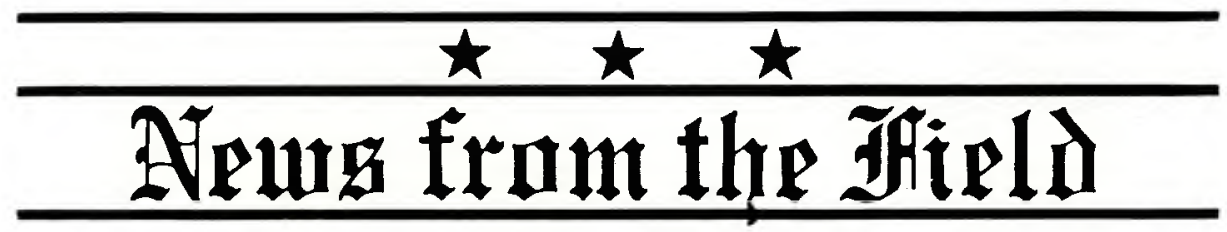

\section{Acquisitions}

- Thirty-five Center for Research Libraries member libraries have contributed $\$ 120,000$ for the purchase of the complete microfilm edition of the Sanborn Fire Insurance Maps. The set is now being deposited with the Center and will be available on loan to all Center members. The maps used for filming have been provided by the Library of Congress Geography and Map Division. The microfilm reproduces 623,000 maps of 10,000 American towns and cities for the period 1867-1950, including all 50 states and the District of Columbia. Sanborn maps are large-scale plans that show the outline of each building, street names, street and sidewalk widths, property boundaries, building use, and house and block numbers. Construction details are also noted. Filming by ChadwyckHealey began in January 1983 and will be completed in early 1985 .

- The Emerson College Archives, Boston, has received a collection of theater clippings and reviews covering plays which opened in the Boston area from the late 1890 s through the 1970 s. Donated by theater critic Elliot Norton, these files include reviews written by him for the Boston Herald as well as those written by other critics. Also included are files pertaining to opera and dance performances, and biographical information on noted individuals in the performing arts.

- The Library of Congress Rare Book and Special Collections Division has acquired a copy of Vergil's Opera printed in Venice by Aldus Manutius in 1501. This early printed work contains the first full book use of the letterform known today as italic, and is also the first of a series of classical works printed by Aldus in a format smaller than quarto, making it the first portable secular book in print.

- Rutgers University, New Brunswick, New Jersey, has purchased a collection of criminal justice books and documents from the National Council on Crime and Delinquency, which recently closed its east coast office. The collection includes approximately 8,000 books, 400 bound periodical volumes, 37,000 published and unpublished reports, 3,000 newspaper clippings, 175 subscriptions to criminal justice serials, and 6,000 documents on microfiche. Annual statistical reports from municipal, state, and federal agencies, original research projects and doctoral dissertations from American universities are among the valued primary source 